however, perceivable around the joint, but the usual means of reatment had completely failed to relieve the symptoms. the had been sent to Mr. Fergusson to have the excision of he joint performed, and the case was considered by that entleman fit and proper for the operation.

On the 27 th of November, 1852 , the patient was brought nto the theatre, and being put under the influence of chloroorm, the operation was performed in the usual manner-that $\dot{s}$, by the $H$ incision at the posterior part of the joint, and the sawing off of the articulating processes of the humerus, Ina, and radius. When these were examined, no trace of artilage was found; the synovial membrane had assumed the celatiniform degeneration, and the bones were covered with bose, flabby granulations. The hæmorrhage was pretty consderable; some vessels were tied, and the wound secured in ihe usual manner.

\section{ST. BARTHOLOMEW'S HOSPITAL.}

Diseased Elbow-Joint; Removal of the Olecranon and Coronoid Process.

(Under the care of Mr. Staniex.)

THIs case, and the one which shall be subjoined, are perhaps still more instructive than the foregoing, for they show how protracted may be the period of repair, and how unsatisfactory cases of excision may sometimes turn out. No doubt that the more or less strumous disposition of the patient has a decided influence on the result; and it unfortunately occurs extremely often, that the most scrofulous subjects are the very ones visited by disease of the joints. By removing portions of bone in a carious and denuded state, and by cutting away the thickened and gelatinous mucous membrane, we unfortunately do not eradicate the mischievous strumous diathesis, which may eventually manifest itself by some other pathological manifestation. It would thus appear that it is only from tolerably well-constituted patients that we can reasonably expect pretty favourable results; and we should always anticipate the worst, where scrofula (this offspring of syphilis according to some anthors) has taken root. We remember seeing this patient very frequently, and his looks were of that peculiarly languid and inactive kind, which renders severe symptoms after a slight injury probable, and a recovery after operation doubtful.

The patient is a young man, about twenty-four years of age, and a carpenter by trade, who was admitted in June, 1850, under the care of Mr. Stanley. Five years before admission he received a blow on the elbow; this injury gave rise to inflammation and its consequences, and the joint remained rather stiff; when, a few weeks before he was first seen, he fell upon a piece of wood, the elbow coming violently in contact with the hard substance. The abscesses, which now formed, left two fistulous openings, one leading to the olecranon, the other, it was feared, communicating with the humerus.

The joint was found on admission to be considerably swollen, the arm semi-flexed, and the motions of the articulation almost null. The question now raised by Mr. Stanley, was, whether the diseased state of the joint was likely to cure itself, or whether the patient's limb might be rendered firm and usefu by surgical interference. And next to these inquiries, it re mained to be discovered whether the disease was confined to the olecranon, or included both the humerus and radius.

Mr. Stanley, having fairly considered these points, consulted with his colleagues, and having laid the matter plainly before the patient, resolved to remove by operation whatever portion of the joint shonld be found diseased when the bones wer exposed.

The patient was brought into the theatre on the 22 nd of June, 1850 , and atter chloroform had been administered, Mr. Stanley made two longitudinal incisions on each side of the joint, about four inches in length, the centre of which were comnected by a transverse cut which ran across the olecranon, the whole presenting the figure of an $\mathbf{H}$ on the posterior part of the articulation. Mr. Stanley made his incision of this extent, as it might have been necessary to remove the whole of the articulation. This mode of bringing the parts into view, which was first advised by Moreau, lias the advantage of affording the surgeon plenty of room and a full command of the joint.

After having dissected back the flaps, Mr. Sianley found that the olecranon was affected with caries; this process of bone was sa wn off and removed. The condyles of the humerus were then examined, and found covered with granulations; some of these were dissected away, but the hone itself, being healthy, was not interfered with. The coronoid process now fixed attention, and this portion of the ulna being found diseased, was sawn off, and a few pieces of the shaft of the bone were likewise removed by means of the pliers.

During the ablation of these various processes, the greatest care was used to avoid wounding either the ulnar nerve of the brachial artery. The former is of course more exposed to the knife than the latter, as the artery is protected by tase brachialis anticus muscle.

Mr. Stanley remarked, after the lips of the wound had been brought together by points of suture, and the patient removed that in cases like the present it was very desirable that more bone should be removed than was actually diseased, for the less osseous substance was taken off, the more useful the limb would be after cicatrization. As the joint would probably be eventually fixed, it was desirable that the most canvenient and most serviceable shape should be given to the arm. Mr. Stanley therefore placed the latter in the semiflexed position, and though the limb might remain stiff, the patient would be far better off than if the limb had been amputated.

The partially favourable results which Mr. Stanley had lately obtained after excision of the head of the humerus, The Lancet, vol. i. 1851 , p. 265, were well calculated to make him persevere in the same line of practice.

The patient had a good deal of pain during the first week, but about thirty days after the operation the longitudinal incision was cicatrized, but the transverse presented a granular ting appearance, about two inches and a half broad across the arm. The discharge was at first extremely abundant, but gradually diminished and became of a laudable description. The patient slept well, and his appetite improved.

It may here be noticed that the union of parts after $t$ the operation is very far from proceeding at the same pace as after amputation of a limb; the action does not seem to be of a vigorous character, and the lines of cicatrization often present a thick and profusely granulating, flabby-looking cord.

The patient's arm was after a few weeks placed on spliats calculated to steady the limb, and exercise no pressure upon the elbow. The apparatus was composed of two splints of the usual width, one fitting the arm to within about three incher from the elbow, and the other the same length of the fore-arm. The lower extremity of the first splint is connected with the upper margin of the second by two rods, about a quarter an inch in diameter, which are attached to the boards at right angle, but soon form another angle of the same kind and running parallel to the splints. The rods thus keep the splints, and consequently the arm, in a fixed position, without touching the latter, and allow some space for any necessary application.

On October 25, 1850, four months after the operation, the lines of incision were almost healed, the $H$ being well marked. and the general health good. Several apertures along the lines of cicatrization were still observed, but the discharge was not profuse. The patient went soon afterwards into the country. February 14, 1851, about eight months after the operation, the patient returned from Brighton; the wound was partially healed up, but remained open in three places, which discharge freely. The size of the articulation has diminished, though it feels hard and lardaceous, of purple colour, and the skin very thin.

The patient was soon afterwards discharged, and no certain tidings of his farther progress could be obtained.

Chronic Inflammation of the Elbow-joint; Exploration of the joint without removal of bone.

The patient is a young girl, about twenty-two years of $2 \mathrm{gec}^{\mathrm{s}}$ who had been labouring under chronic inflammation of the elbow-joint for several months past. She presented all the outward signs of flourishing health, and was treated by the remedies usual in such cases, until it was palpable that sort of benefit was being derived. She had been admitted in October, 1851, and on Nov. 8, of the same year, MIr. Stanley had the patient brought into the theatre. When she had been placed under the influence of chloroform the joint was laid bare by means of an incision at the posterior part, from one condyle to the other. The flap was dissected upwards, and Mr. Stanley intended to take off as much of the articulating surfaces as would be found in a diseased condition. When the bones were examined, they were discovered to be stadder with granulations; a tew of these were removed, and it was thought that the joint might recover a healthy action, and become partly anchylosed, if the parts were left undisturbed, as the large incision would have the effect of changing the nutrition of the textures; the case being thus treated on the principle advocated by Mr. Gay, of the hoyal Free Hospital 
The patient progressed for a time pretty favourably, but months passed before any distinct improvement could be noticed in the part. She remained a considerable period in Sitwell ward, and was finally sent into the country, June 11, 1852, about seven months after the operation, the wound not being completely healed.

These two cases offer this very remarkable peculiaritythat in the first, the lower articular process of the humerus was covered with granulations, and not removed; and in the second, the whole of the joint was in the same granulating state, and not disturbed. The idea then obtrudes itself, whether sparing these parts had anything to do with the slow progress of the cases. We do not pretend to solve the problem, but facts like these are extremely valuable, and we have therefore annexed them with great pleasure to the present series.

[The cases of excision of the elbow-joint, as tabulated at the head of the present " Mirror," will be continued next week.]

\section{aReniéns and Notíces of dgooks.}

An Essay on the Action of Medicines in the System; or, "On the Mode in which Therapeutic A gents introduced into the Stomach produce their peculiar Effects on the Animal Economy." Being the Prize Essay to which the Medical Society of London awarded the Fothergillian Gold Medal for 1852. By Frederick William Hraduand, B.A., M.R.C.S., \&c. 8vo, pp. 346. London. 1852.

THIs is a book after the critic's own heart. Treating of a subtle point, which has in almost all ages and countries occupied the attention of medical and chemical philosophers, Mr. Headland has struck out a path for himself, and has thereby not only shown how much remained to be done, how many of our hypotheses as to the action of medicines were grounded on the insecure foundation of bare assertion; but by his laborious essay has put the present views of therapeutists in a clear light, and by his own experiments and observations has removed some of the many deep obscurities which have so long surrounded the subject. That many of the misnamed facts in medical science are totally destitute of logical proof, must be allowed by all unbiassed observers; and it cannot but be with temporary feelings of regret, that many a man of science has found that the more he learnt, the more apparent became his ignorance. A sure harvest will accrue, however, not only to each observer who strives zealously after truth, but through him to his profession; and though the rewards of severe labour may not be reaped as speedily as may be desired, still success and honour will assuredly fall to the lot of him who earnestly strives to merit distinction.

Mr. Headland has not been unmindful of the many difficulties by which his subject is encompassed; at the same time he has not been dismayed. In order to give clearness and precision to his remarks, as well as to render them easily intelligible, he has arranged the heads of his ideas on the action of medicines in the form of a number of distinct propositions, each of which he attempts to prove separately, as if it were a theorem in geometry; while occasionally, by subdividing a postulate into a number of minor arguments, and distinctly verifying each, he strengthens very materially the grounds upon which he reasons. Prior to attempting to give our readers some idea of the work before us, it may probably serve to render our remarks more clear, if we at once put them in possession of the classification of medicines adopted by $\mathrm{Mr}$. Headland, observing that it is founded on the supposed mode of action of drugs after they have entered the blood. $\mathrm{He}$ divides them thus:-

$$
\begin{aligned}
& \text { "Class 1.-H Hmatica. } \\
& \text { Div. 1.-Restcurantia. }
\end{aligned}
$$

Ordo 1. Alimenta.

Ordo 2. Acida.

Ordo 3. Alkalia.
Ordo 4. Tonica

Ordo 5. Chalybeata.

Ordo 6 . Solventia.
Ordo 1. Antiphlogistica.

Ordo 2. Antisy philitica.

Ordo 3. Antiscrofulosa.

Ordo 4. Antiarthritica.

Class 2.-NeURoTica.

Div. 1.-Stimulantia.

Ordo 1. Stimulantia Generalia

Ordo 2. Stimulantia Specifica.

Div. 2.-Narcotica.

Ordo 1. Inebriantia.

Ordo 2. Somnifera.

Ordo 3. Deliriantia.

Div. 3.-Sedantia.

Ordo 1. Sedantia Generalia.

Ordo 2. Sedantia Specifica.

Class 3.-Astringentia.

Ordo 1. Astringentia Mineralia.

Ordo 2. Astringentia Vegetabilia.

Class 4.-Elminantia.

Ordo 1. Sialogoga.

Ordo 2. Expectorantia. Ordo 5. Diaphoretica.

Ordo 3. Cathartica.

Ordo 6. Diuretica."

Such being the classification laid down, let us proceed to examine Mr. Headland's treatise more in detail. To commence then at the beginning, we may notice that the essay opens with an excellent chapter of Introductory Remarks, in which, after alluding to the great importance and extent of the subject, we find some observations tending to prove, what all will allow to be true, that a correct appreciation of the action of medicines is an essential requisite to the advancement and perfection of medical science. In the second chapter the anthor takes a brief review of the opinions of those writers who have preceded him in the same class of investigations, by means of which retrospect an attempt is made to draw the line between that which is known and unknown-between that which has been ascertained and that which may be debated-between that which is approved and that which is condemned. TWe here also find considered the principal classifications of medicines which have been proposed up to the present time. In the third chapter we come to the real subject-matter of the essay, and have our author's own conclusions as to the modus operandi of drugs. Supposing that a remedy has been already introduced into the stomach, its history is considered from the beginning to the end of its course, by means of a series of ten propositions, which we here extract. The arguments adduced to prove these postulates our readers must seek for themselves, and we can only say that they will be well repaid for their trouble.

"Proposition 1 affirms then-That the great majority of medicines must obtain entry into the blood, or internal fluids of the body, before their action can be manifested.

"Prop. 2.-That the great majority of medicines are capable of solution in the gastric or intestinal secretions, and pass, without material change, by a process of absorption, through the coats of the stomach and intestines, to enter the capillaries of the portal system of veins.

"PROP. 3. That those medicines which are completely insoluble in water, and in the gastric and intestinal juices, cannot gain entrance into the circulation.

"Prop. 4. That some few remedial agents act locally on the mucous surface, either before absorption, or without being absorbed at all. That they are chiefly as follows-

a. Irritant emetics.

b. Stomach anæsthetics.

c. Irritant cathartics.

"Prop. 5. That the medicine, when in the blood, must permeate the mass of the circulation, as far as may be required to reach the parts on which it tends to act. That there are two possible exceptions to this rule:-

$a$. The production of pain or sensation at a distant point.

$b$. The production of muscular contraction at a distant point 